\title{
Experimental trial on the electrical characteristics of photovoltaic panels under the effect of a simulated failure
}

\author{
M.C. Sekkal ${ }^{*}$, S. Belhachi, F.I. Touati, S. Saada and Z. Ziani \\ Department of Technical Sciences, Institute of Science and Technology, University Center - SALHI Ahmed, Naâma, Algeria
}

\begin{abstract}
In this work we measure electrical characteristics of different panels following the addition of a simulated failure, namely cracks on the protective layer of photovoltaic cells. The objective is to see its influence on the electrical production of panels on one side, and to see if it is possible to diagnose this failure on the other. The cracks are simulated using broken transparent plates that will be positioned on each solar panel before measuring its real characteristics. The results show that despite the continuity of the operation of the photovoltaic equipment in the presence of cracks, those last clearly influence the electrical power supplied by the panel. Among other things, they give a very particular form to its I-V characteristic which can be used to detect this failure.
\end{abstract}




\section{Introduction}

Subject to sunlight and bad weather, materials of photovoltaic panels gradually degrade. Currently, the useful life of photovoltaic panels is potentially guaranteed for 25 to 30 years. Therefore, there is limited interest in studying aspects of their useful life [1]. Beyond this period, the panel continues to operate but its productivity decreases over time.

According to systematic tests, achieving by manufacturers for years, this useful life will be attained in most cases. However, there are wide variations from one manufacturer to another and even from one production to another within the same manufacturing company. While there are examples of older panels still operating at $80 \%$ of their original capacity after 40 years, it must be admitted that modern panels do not use the same materials or the same manufacturing methods. The results could therefore be different [2].

The useful life of photovoltaic solar panel and its reliability depend heavily on its breakdowns and usual failures, their diagnostics and the speed at which they are taken care of. A good regular maintenance often makes possible to exceed the 25 years of service life promised by the manufacturers. We then speak about mean time before failure of photovoltaic modules, often designated by its acronym: MTBF - PVm [3].

The solar industry typically lacks comprehensive public data sets on the performance of PV equipment. Indeed, of more than $300 \mathrm{GW}$ of global capacity in $2017,78 \%$ have been installed for less than five years. Thus, there were few aging solar panels on which we could estimate long-term longevity. The industry standard 25-year warranty was only introduced in 1997 and no module it covers has yet reached that age [2].

Nevertheless, a series of articles concerning the degradation, reliability and performance of photovoltaic panels on site [4], and under different climatic and technological conditions [5] in relation to their failures [6] have been published. As well as an exhaustive bibliographic study on the degradation rates of these PV modules [7] cited in the 2017 report on the reliability of PV modules [8] from the DNV GL group. These studies were carried out on panels which have sometimes reached 30 years of service life.

In this work we measure electrical characteristics of different panels following the addition of a simulated failure, namely cracks on the protective layer of photovoltaic cells. The objective is to see its influence on the electrical production of panels on one side, and to see if it is possible to diagnose this failure on the other. The cracks are simulated using broken transparent plates that will be positioned on each solar panel before measuring its real characteristics.

A similar work which dates from 2012 excites, where failures on chains of PV modules are diagnosed by measuring the I-V characteristics of these modules on the two regions of the curve: voltage dependence and current dependence [9].

The rest of the article is organized as follows: Section 2 is consecrated to the practical study of the influence of cracks on the change of electrical characteristics and the decrease in efficiency of solar panels. The results are discussed in section 3, and we give conclusion and some perspectives in section 4 .

\section{Practical study}

\subsection{Materials and methods}

The present study attempts to propose a method for detecting a failure of photovoltaic panels by observing its influence on their characteristics. The idea is to compare their general electrical characteristics with and without the cracks.

To achieve this work, we focus first on the behavior of PV panels under fixed lighting between 100 and $1000 \mathrm{~W} / \mathrm{m}^{2}$ and at a temperature of $25^{\circ} \mathrm{c}$ (standard operating conditions) as shown in experiences 1 and 2, and under real conditions (experience 3 ).

Then, transparent plates with cracks of varying scales are introduced, and the readings of the new electrical characteristics are compared with that of the witness experiments (1-2 and 3).

- Five (05) plates of dimension $7 \times 15 \mathrm{~cm}^{2}$ containing different scales of cracks, numbered according to the proportion of cracks (1: very little cracks - 5: Completely cracked) were used (Figure 1).

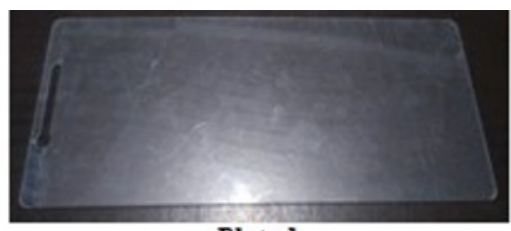

Plate 1

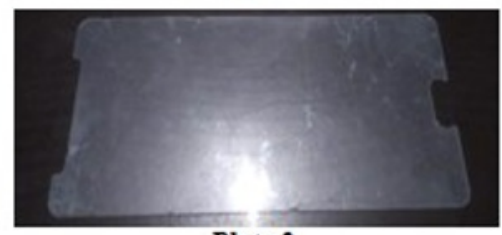

Plate 2

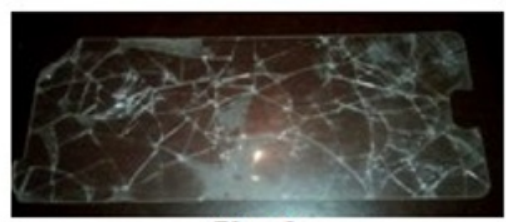

Plate 3

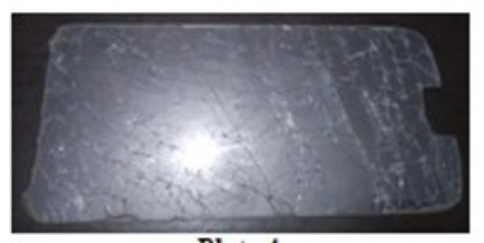

Plate 4

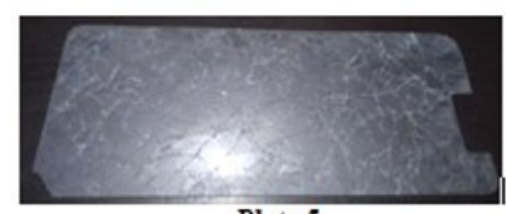

Plate 5

Fig. 1. The cracked plates. 
- Three (03) photovoltaic panels with different sizes corresponding to the three witness experiments were used :

Witness experiment No. 1: Panel of dimension $12.6 \times 9.4 \mathrm{~cm}^{2}$, with eight $(08)$ cells, subjected to a radiation of $120 \mathrm{~W} / \mathrm{m}^{2}$ (Figure 2).

Witness experiment No. 2: Panel of dimension $32 \times 21 \mathrm{~cm}^{2}$, consists with 72 cells and inclined at an angle of $49.7^{\circ}$. The temperature sensor (pyrometer) at the study site is tilted at the same angle (Figure 3).

Witness experiment No. 3: Panel of dimension $0.8 \times 1.75 \mathrm{~m}^{2}$ (real model) under real conditions (Figure4):

- Test $N^{\circ}$ 1: Temperature of $27{ }^{\circ} \mathrm{C}$ and solar radiation of $892 \mathrm{~W} / \mathrm{m}^{2}$.

- Test $N^{\circ}$ 2: Temperature of $20^{\circ} \mathrm{C}$, radiation of $260 \mathrm{~W} / \mathrm{m}^{2}$ and an inclination of $25^{\circ}$.

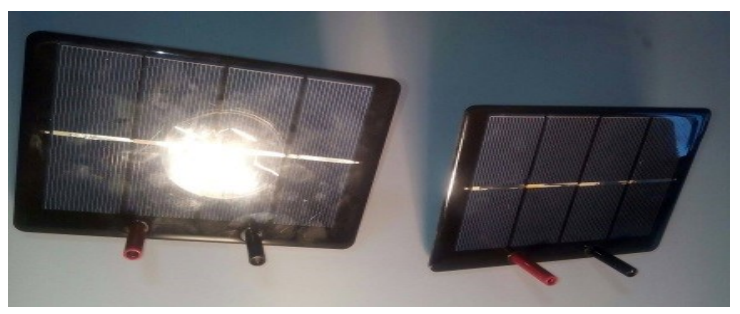

Fig. 2. Photovoltaic panel of the first experiment.

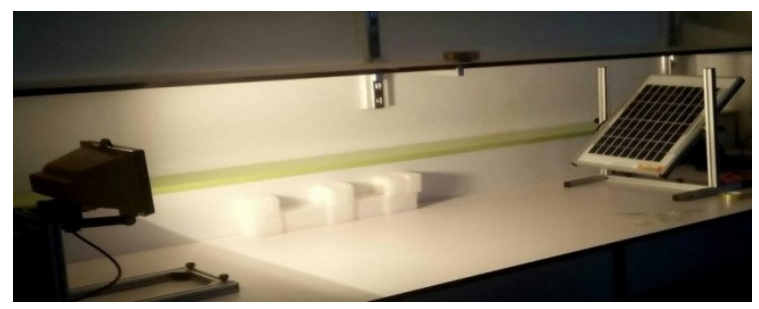

Fig. 3. Photovoltaic panel of the second experiment.

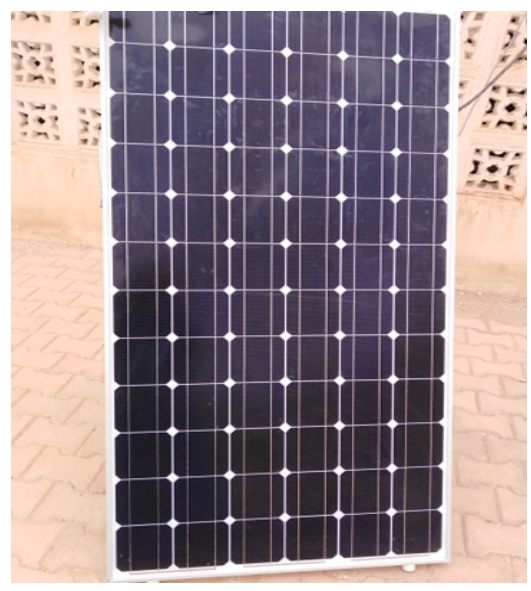

Fig. 4. Photovoltaic panel of the third experiment.

- The photovoltaic panel analyzer (Figure 5) makes possible to trace the I - V characteristic and to note the various electrical values associated to the operation of the panel: the open circuit voltage (Vopen); circuit short current (Ishort); the max current, the max voltage and the max power; energy efficiency (EFF) and form factor (FF). It also gives, when a load is connected, the coordinates $(\mathrm{V}, \mathrm{I}, \mathrm{P})$ of the operating point.

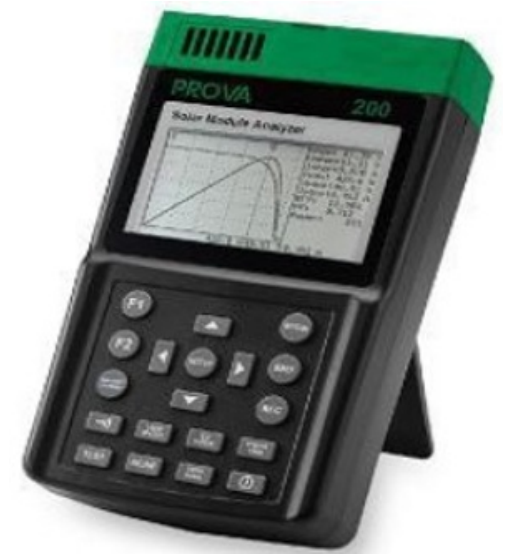

Fig. 5. The photovoltaic panel analyzer.

\subsection{Results presentation}

By placing successively the cracked plates on the panels, we obtain their characteristics in degraded mode. Figures 6, 7 and 8 show the comparisons between the characteristics of the three types of panels in normal mode and under failure condition.

\section{Results discussion}

The results of the three experiments are summarized in the tables bellow. Figures 9 and 10 give graphical representations of these results.

- Experiment No. 1:

We note that almost all the curves decrease monotonously, which confirms the correlation between the size of the cracks and the decrease in the electrical production (more there are cracks, more the electrical production characteristics decrease).

The maximum voltage (Vmax) and the form factor (FF) oscillate around their average values which are 1.762 Volt and 0.7967 . Therefore they cannot be considered as a health indicators for the failure mode: cracks on the photovoltaic panels.

\section{- Experiment No.2:}

Except a few minor irregularities, Experiment 2 confirms the results of Experiment 1: almost all the curves decrease monotonously, which confirms the correlation between the size of the cracks and the decrease in the electrical production. The maximum voltage (Vmax) and the form factor (FF) oscillate around their average values which are 16.64 Volt and 0.7939. The FF is relatively stable. These two quantities cannot be health indicators for this failure mode.

It is also noted that, if the cracks are small (plates 1 and 2), the reduction in yield is small too, and the losses are not as great as for the first experiment. This means that the dimension of panels compared to the size of the cracks plays a role in the change of PV modules electrical characteristics. 

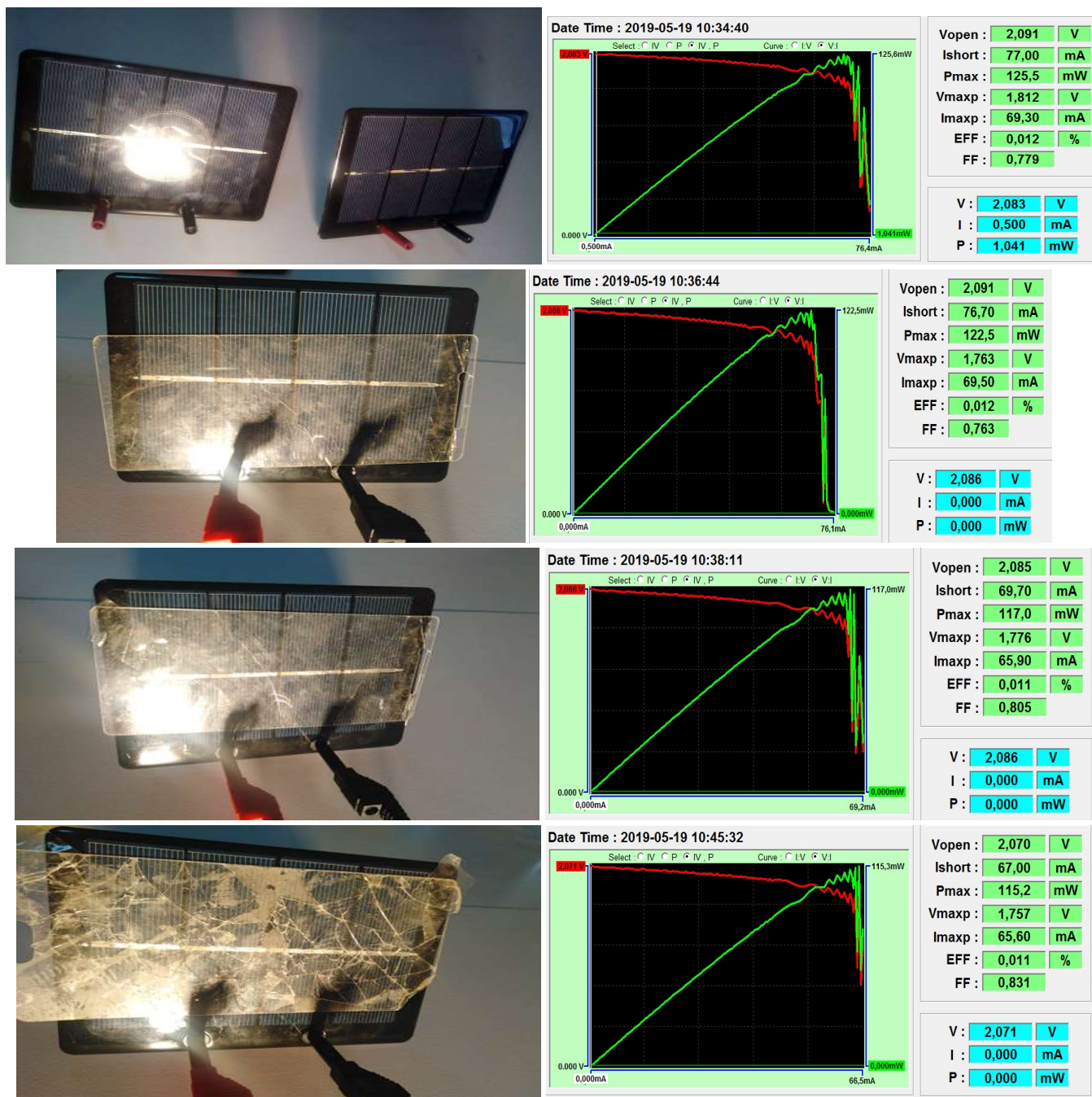

Vopen : $2,085 \quad \mathrm{~V}$

Ishort: $69,70 \quad \mathrm{~mA}$

$P \max : 117,0 \mathrm{~mW}$

\begin{tabular}{lll} 
& \\
$V \operatorname{maxp}$ & 1,776 & $V$ \\
\hline
\end{tabular}

$\operatorname{Imaxp}: 65,90 \mathrm{~mA}$

EFF : $0,011 \%$

$\mathrm{FF}: 0,805$

\begin{tabular}{ll|l|l|}
$\mathrm{V}:$ & 2,086 & $\mathrm{~V}$ \\
$\mathrm{I}:$ & $\mathbf{0 , 0 0 0}$ & $\mathrm{mA}$ \\
\hline
\end{tabular}

P: $0,000 \mathrm{~mW}$

Date Time : 2019-05-19 10:45:32

Vopen : $2,070 \quad \mathrm{~V}$

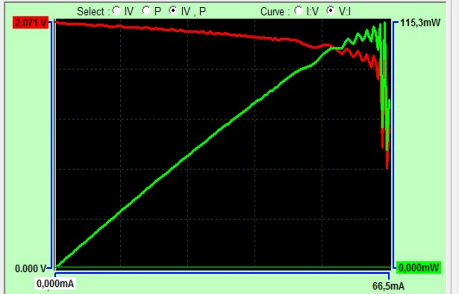

short : $67,00 \mathrm{~mA}$

Pmax : $115,2 \mathrm{~mW}$

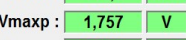

$\operatorname{maxp}: \quad 65,60 \mathrm{~mA}$

EFF : $0,011 \quad \%$ FF : 0,831

\section{$\mathrm{V}: 2,071 \mathrm{~V}$ \\ I: $0,000 \mathrm{~mA}$ \\ $\mathrm{P}: \quad 0,000 \mathrm{~mW}$}
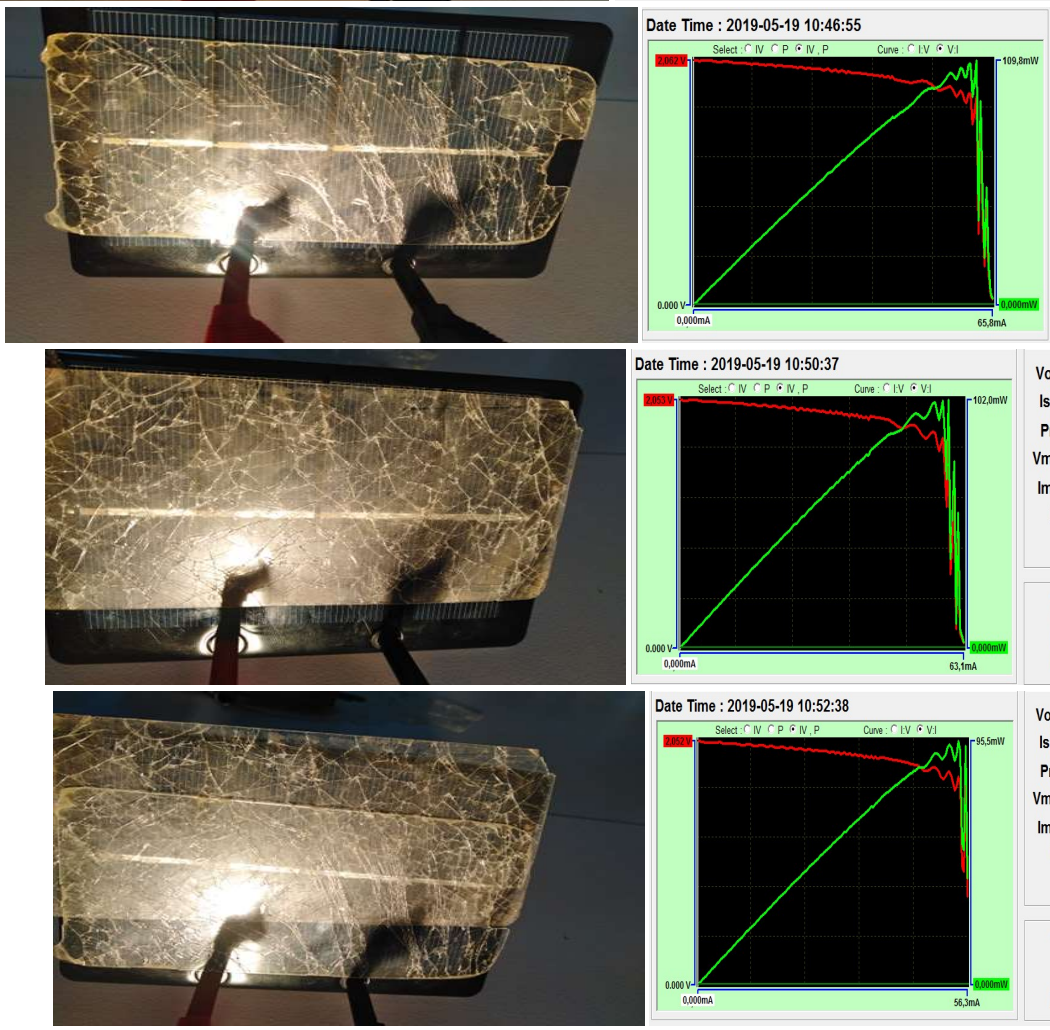

Date Time : 2019-05-19 10:52:38

\section{Vopen : 2,068 V}

Ishort: $66,30 \mathrm{~mA}$

$P \max : \quad 109,8 \mathrm{~mW}$

$V \operatorname{maxp}: 1,763 \quad V$

$\operatorname{Imaxp}: \quad 62,30 \mathrm{~mA}$

EFF : $0,010 \%$

FF : 0,801

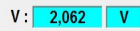 \\ I: $0,000 \mathrm{~mA}$ \\ $\mathrm{P}: \quad 0,000 \mathrm{~mW}$}

\section{Vopen: 2,060 V \\ Ishort: $63,60 \mathrm{~mA}$ \\ $P \max : 102,0 \mathrm{~mW}$ \\ $V \operatorname{maxp}: 1,709 \quad \mathrm{~V}$ \\ $I \operatorname{maxp}: 59,70 \mathrm{~mA}$ \\ EFF : $0,010 \%$ \\ $\mathrm{FF}: 0,778$

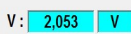 \\ I: $0,000 \mathrm{~mA}$ \\ $P: \quad 0,000 \mathrm{~mW}$}

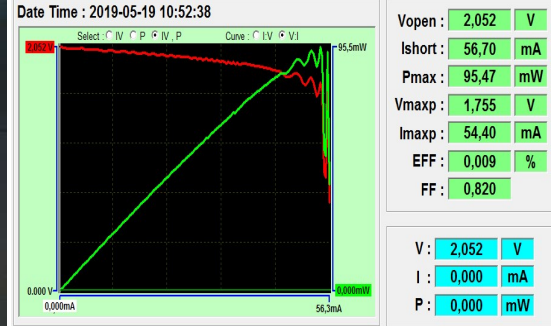

Fig. 6. Results of experiment No. 1: Electrical characteristics of the first type of photovoltaic panels in normal state and with the cracked plates. 


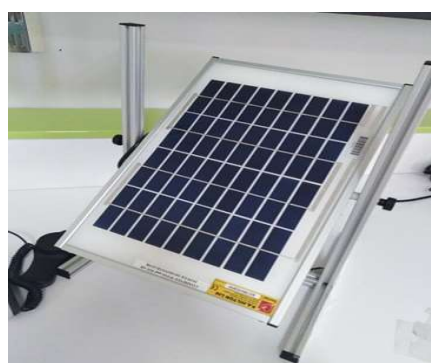

Date Time : 2019-05-13 10:15:11
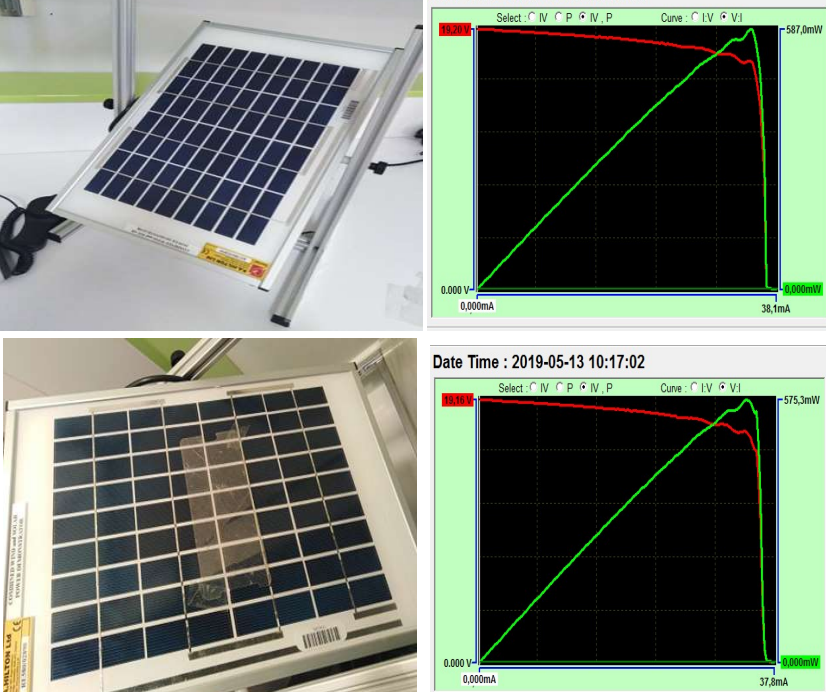

Date Time : 2019-05-13 10:17:02
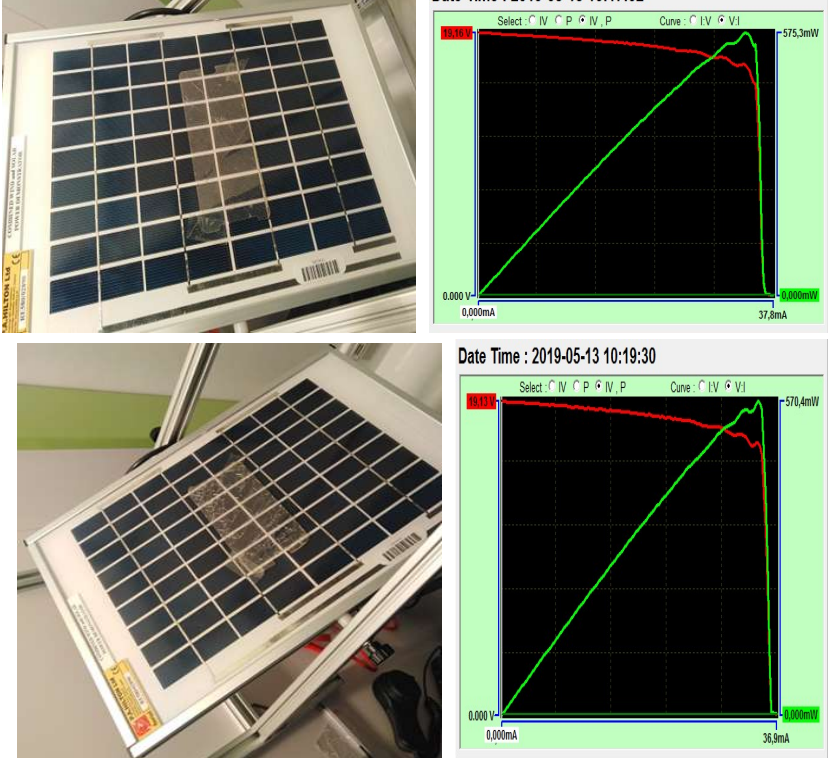

Date Time : 2019-05-13 10:19:30

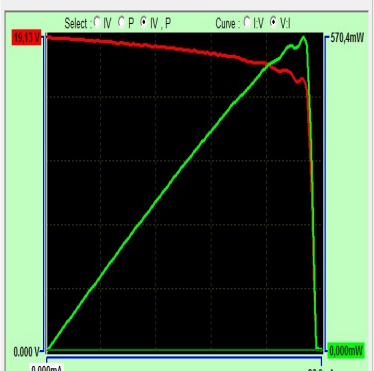

Date Time : 2019-05-13 10:22:54
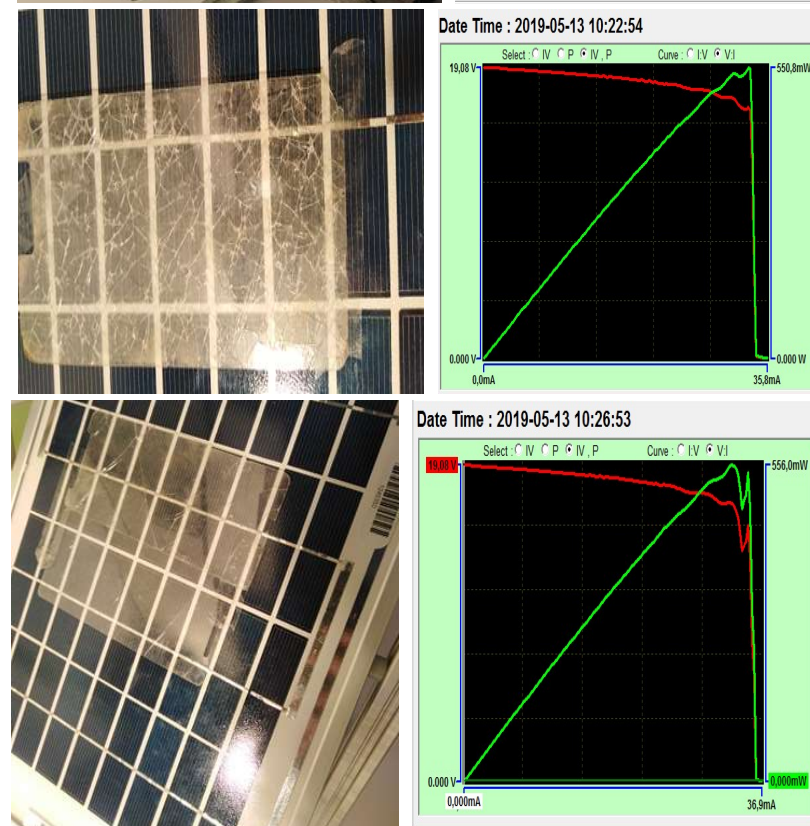

Date Time : 2019-05-13 10:26:53
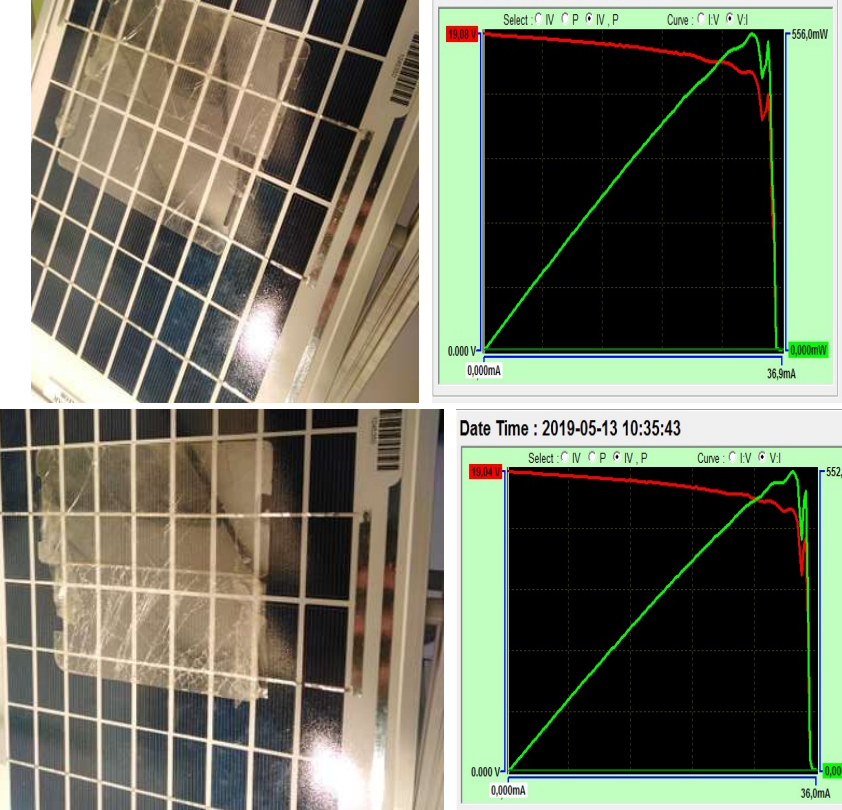

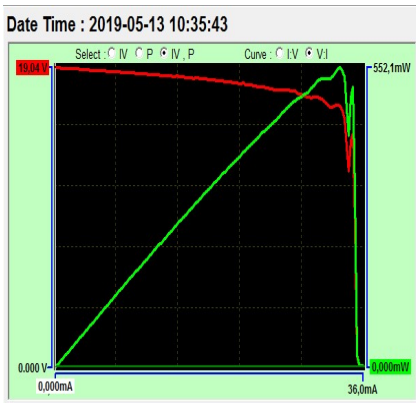

Vopen : \begin{tabular}{c|c|}
19,25 & $\mathrm{~V}$ \\
\hline
\end{tabular}

Ishort: $38,40 \mathrm{~mA}$ $P \max : \quad 587,0 \mathrm{~mW}$

$V \operatorname{maxp}: 16,77 \quad \mathrm{~V}$

Imaxp : $35,00 \mathrm{~mA}$

EFF : $0,058 \%$

FF : 0,793

\section{$\mathrm{v:}:$\begin{tabular}{c|c|}
19,20 & $\mathrm{~V}$ \\
\hline
\end{tabular} \\ I : $0,000 \mathrm{~mA}$ \\ P: $0,000 \mathrm{~mW}$}

Vopen : \begin{tabular}{|c|c|}
\hline 19,20 & $\mathrm{~V}$ \\
\hline
\end{tabular}

Ishort: $38,10 \mathrm{~mA}$

$P \max : \quad 575,3 \mathrm{~mW}$

$V \operatorname{maxp}: \quad 16,82 \quad \mathrm{~V}$

$I \operatorname{maxp}: \quad 34,20 \mathrm{~mA}$

EFF : $0,057 \%$

FF : 0,786

\section{\begin{tabular}{ll|l}
$\mathrm{V}:$ & 19,16 & $\mathrm{~V}$ \\
\hline
\end{tabular}}

I: $0,000 \mathrm{~mA}$

P: $0,000 \mathrm{~mW}$

Vopen: $19,15 \mathrm{~V}$

Ishort: $37,20 \mathrm{~mA}$

Pmax: $570,3 \mathrm{~mW}$

$V_{\operatorname{maxp}}: 16,58 \mathrm{~V}$

Imaxp : $34,40 \mathrm{~mA}$

EFF : $0,057 \%$

FF : 0,800

\section{$\mathrm{V}: \overline{19,13} \mathrm{~V}$}

I: $0,000 \mathrm{~mA}$

$P: 0,000 \mathrm{~mW}$

Vopen: $19,1 2 \longdiv { V }$

Ishort: $36,10 \mathrm{~mA}$

$P \max : \quad 550,8 \mathrm{~mW}$

\begin{tabular}{ll|l}
$V \operatorname{maxp}:$ & 16,49 & $\mathrm{~V}$ \\
&
\end{tabular}

$I \operatorname{maxp}: \quad 33,40 \mathrm{~mA}$

EFF : $0,055 \%$

FF : 0,797

$\mathrm{V}: \quad \ldots-\cdots$

\begin{tabular}{ll|l|}
$\mathrm{I}:$ & $\cdots$ & $-\cdots$ \\
$\mathrm{P}:$ & $\cdots$ &..-- \\
\hline
\end{tabular}

Vopen: 19,09 V

Ishort: $37,20 \mathrm{~mA}$

$P \max : \quad 556,0 \mathrm{~mW}$

$V \operatorname{maxp}: 16,74 \quad V$

Imaxp: $\quad 33,20 \mathrm{~mA}$

EFF: $0,055 \%$

FF : 0,782

$\mathrm{V:} \quad 19,08 \mathrm{~V}$

1: $0,000 \mathrm{~mA}$

$P: 0,000 \mathrm{~mW}$

Vopen : $19,05 \quad \mathrm{~V}$

Ishort: $36,30 \quad \overline{m A}$

Pmax: $552,1 \mathrm{~mW}$

\begin{tabular}{cl|l|}
\hline maxp $:$ & 16,58 & $V$ \\
\hline
\end{tabular}

$I \operatorname{maxp}: \quad 33,30 \mathrm{~mA}$

EFF : $0,055 \%$

FF : 0,798

V: $19,04 \quad \mathrm{~V}$

I: $0,000 \mathrm{~mA}$

$\mathrm{P}: 0,000 \mathrm{~mW}$ 

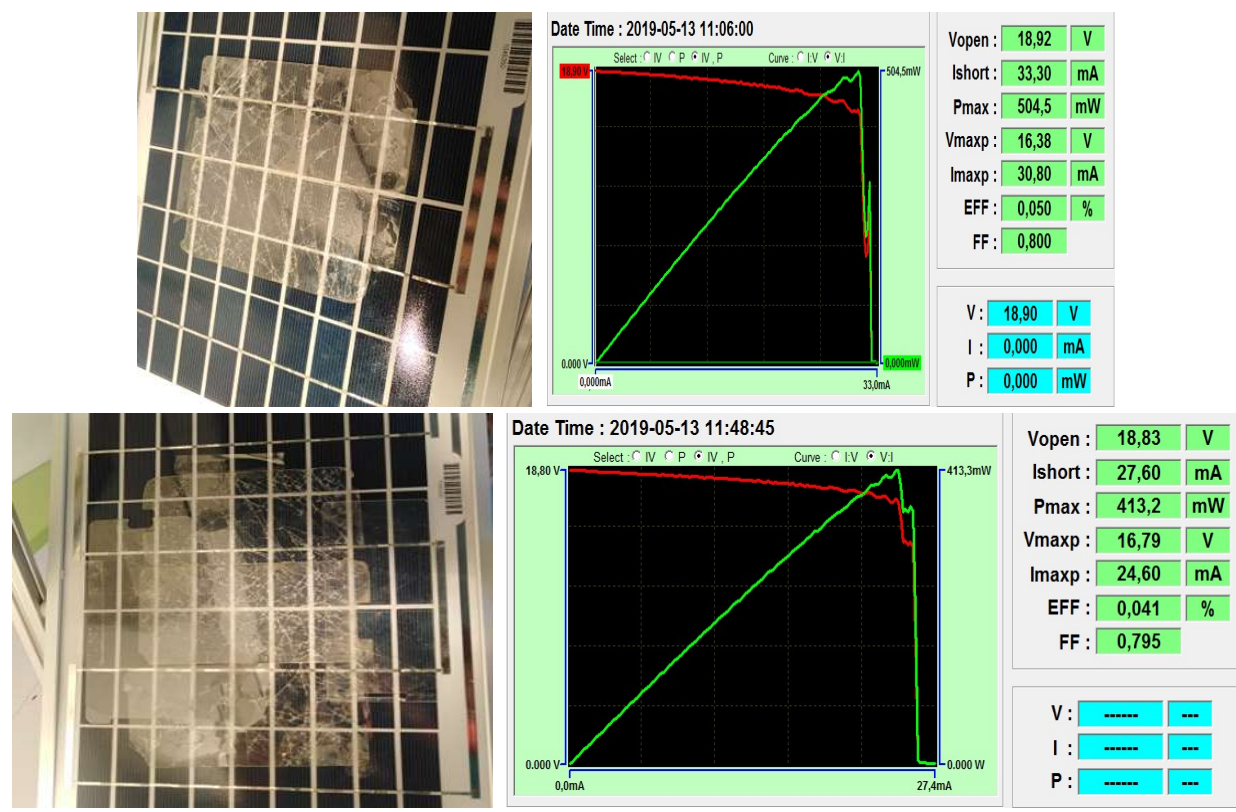

Fig. 7. Results of experiment No. 2: Electrical characteristics of the second type of photovoltaic panels in normal state and with the cracked plates
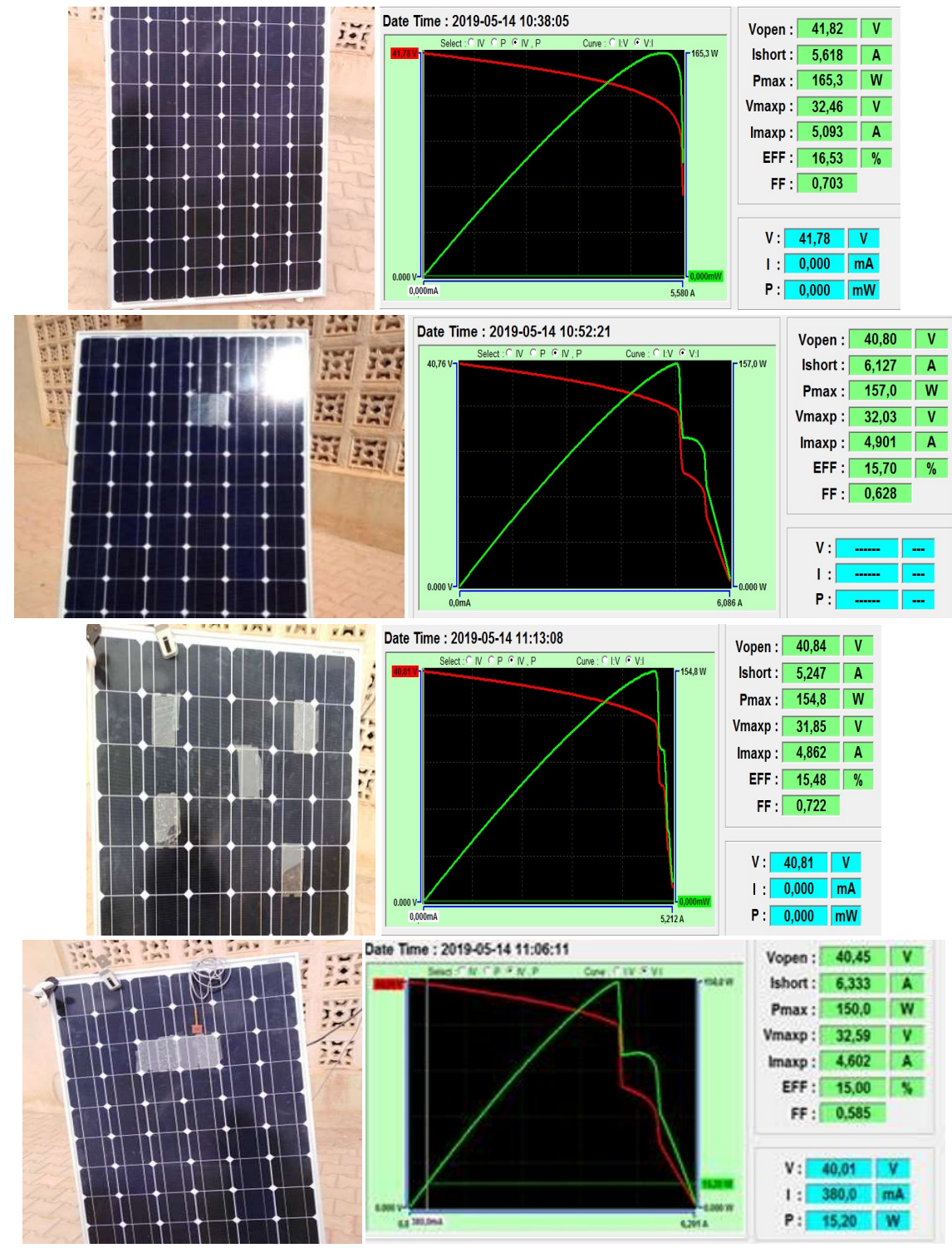

Fig. 8. Results of experiment No. 3: Electrical characteristics of the third type of photovoltaic panels in normal state and with the cracked plates 
Table 1. Recapitulation of experiment No.1 results.

\begin{tabular}{|c|c|c|c|c|c|c|c|}
\hline Plates & $/$ & $\mathbf{1}$ & $\mathbf{2}$ & $\mathbf{3}$ & $\mathbf{4}$ & $\mathbf{5}$ & $\mathbf{4 - 5}$ \\
\hline Vopen (V) & 2.091 & 2.091 & 2.085 & 2.070 & 2.068 & 2.060 & 2.052 \\
\hline Ishort (mA) & 77.0 & 76.7 & 69.7 & 67.00 & 66.30 & 63.6 & 56.7 \\
\hline Pmax (mW) & 125.5 & 122.5 & 117.0 & 115.2 & 109.8 & 102.0 & 95.47 \\
\hline Vmax (V) & 1.812 & 1.763 & 1.776 & 1.757 & 1.763 & 1.709 & 1.755 \\
\hline Imax (mA) & 69.3 & 69.5 & 65.9 & 65.6 & 62.30 & 59.7 & 54.40 \\
\hline EFF & 0.012 & 0.012 & 0.011 & 0.011 & 0.010 & 0.010 & 0.009 \\
\hline FF & 0.779 & 0.763 & 0.805 & 0.831 & 0.801 & 0.778 & 0.820 \\
\hline
\end{tabular}
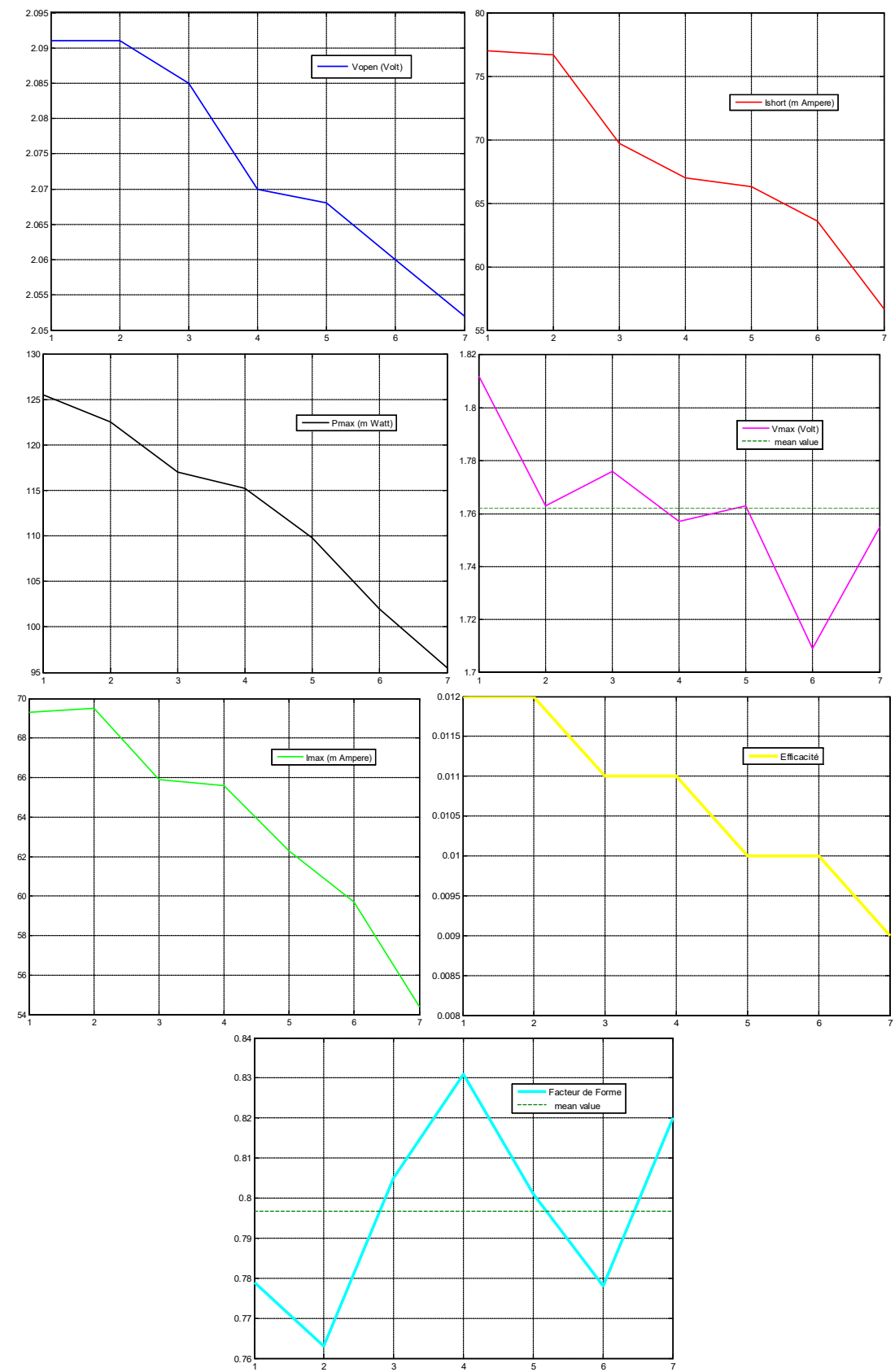

Fig. 9. Graphical representation of the experiment 1 results. 
Table 2. Recapitulation of experiment No.2 results.

\begin{tabular}{|c|c|c|c|c|c|c|c|c|}
\hline Plates & $/$ & $\mathbf{1}$ & $\mathbf{3}$ & $\mathbf{5}$ & $\mathbf{1 - 2}$ & $\mathbf{1 - 4}$ & $\mathbf{3 - 4}$ & $\mathbf{1 - 2 - 3 - 4 - 5}$ \\
\hline Vopen (V) & 19.25 & 19.2 & 19.15 & 19.12 & 19.09 & 19.05 & 18.92 & 18.83 \\
\hline Ishort (mA) & 38.4 & 38.1 & 37.20 & 36.10 & 37.2 & 36.3 & 33.3 & 27.60 \\
\hline Pmax (mW) & 587.0 & 575.3 & 570.3 & 550.8 & 556.0 & 552.1 & 504.5 & 413.2 \\
\hline Vmax (V) & 16.77 & 16.82 & 16.58 & 16.49 & 16.74 & 16.58 & 16.35 & 16.79 \\
\hline Imax (mA) & 35.0 & 34.2 & 34.4 & 33.4 & 33.2 & 33.3 & 30.8 & 24.60 \\
\hline EFF & 0.058 & 0.057 & 0.057 & 0.055 & 0.055 & 0.055 & 0.05 & 0.041 \\
\hline FF & 0.793 & 0.786 & 0.8 & 0.797 & 0.782 & 0.798 & 0.8 & 0.795 \\
\hline
\end{tabular}
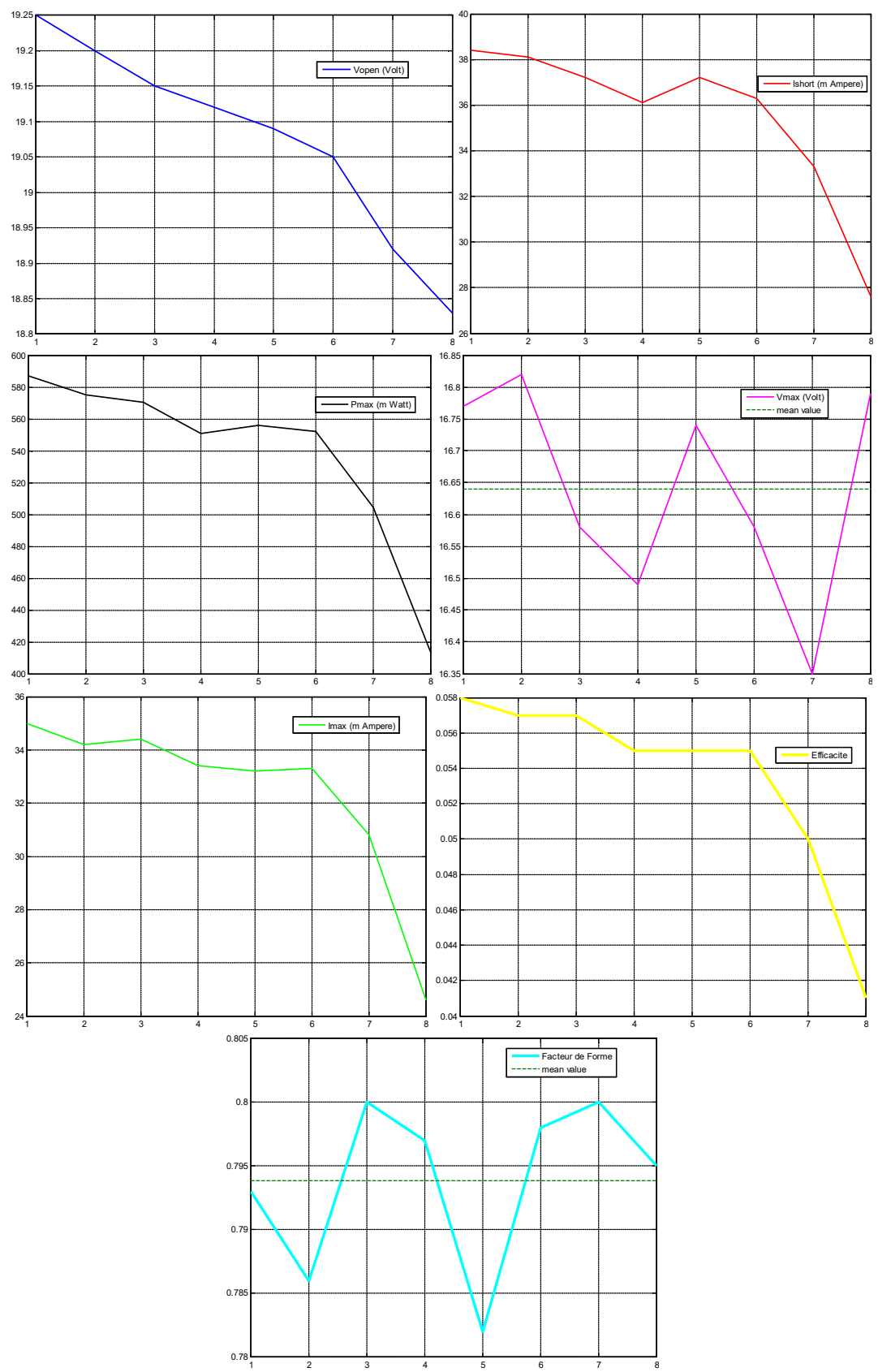

Fig. 10. Graphical representation of the experiment 2 results. 
- Experiment No. 3:

In this experiment we used large solar panels (real model) under real conditions. The experiments were carried out in a limited time period time (less than 40 min) so as not to be affected by the change in sunshine or temperature.

However, these may have affected the results. We found that:

- Plates with few cracks do not introduce significant changes to the electrical characteristics of the panel. This is why several plates are used at the same time for each experiment.

- When the plates are separated, they have less impact than when they are grouped. This means that several small cracks are less harmful than large one.

- No quantity shows a monotonic tendency (except Vopen for test 2). These values cannot be considered as health indicators of the solar panels on site for this failure mode, and cannot be used for the calculation of their remaining useful life (RUL).

Qualitatively, and as in previous experiments, the cracks introduce a symptomatic change in the shape of the I-V characteristic of photovoltaic modules that can be used to diagnose this failure.

The three experiments demonstrated an inverse relationship between the size of the panel and the size of the cracks. For the same plates used on the different panels, we note that: Smaller the size of the panels is, more the cracks influence their electrical characteristics.

Table 3. Recapitulation of experiment No.3 results-Test 1.

\begin{tabular}{|c|c|c|c|c|}
\hline Plates & $/$ & $\mathbf{2 - 3}$ & $\mathbf{2 - 3 4 - 5}$ & $\mathbf{1 - 2 - 3 - 4 - 5}$ \\
\hline Vopen (V) & 41.82 & 40.80 & 40.45 & 40.84 \\
\hline Ishort (mA) & 5.618 & 6.127 & 6.333 & 5.247 \\
\hline Pmax (mW) & 165.3 & 157.0 & 150.0 & 154.8 \\
\hline Vmax (V) & 32.46 & 32.03 & 32.59 & 31.85 \\
\hline Imax (mA) & 5.093 & 4.901 & 4.602 & 4.862 \\
\hline EFF & 16.53 & 15.70 & 15.00 & 15.48 \\
\hline FF & 0.703 & 0.628 & 0.585 & 0.722 \\
\hline
\end{tabular}

Table 4. Recapitulation of experiment No.3 results-Test 2.

\begin{tabular}{|c|c|c|c|c|}
\hline Plates & $/$ & $\mathbf{2 - 3}$ & $\mathbf{2 - 3 4 - 5}$ & $\mathbf{1 - 2 - 3 - 4 - 5}$ \\
\hline Vopen (V) & 42.65 & 42.58 & 42.43 & 42.19 \\
\hline Ishort (mA) & 2.322 & 2.966 & 2.158 & 3.327 \\
\hline Pmax (mW) & 76.93 & 78.99 & 66.98 & 69.29 \\
\hline Vmax (V) & 35.48 & 35.98 & 35.26 & 35.09 \\
\hline Imax (mA) & 2.168 & 2.195 & 1.899 & 1.974 \\
\hline EFF & 7.693 & 7.899 & 6.698 & 6.929 \\
\hline FF & 0.776 & 0.625 & 0.731 & 0.493 \\
\hline
\end{tabular}

\section{Conclusion}

Photovoltaic panels (PVs) are physical components whose real the useful life is greatly influenced by their usual breakdowns and failures, such as cracks, traces, corrosions, delamination, fouling, hot spots ...

I-V characteristics of a photovoltaic panels change, in normal mode, mainly depending on the temperature, lighting, climate change and some electrical phenomena. However, they keep their basic shape.

In this work, we experimentally studied the effect of one of these failures, namely cracks, on the electrical characteristics of photovoltaic panels. This has resulted in a change on the shape of $\mathrm{I}-\mathrm{V}$ characteristic of said panels. This symptomatic change on the shape of $\mathrm{I}-\mathrm{V}$ characteristic of photovoltaic modules can be used to diagnose this failure.

We have also shown in practice that the electrical parameters of the PV change in degraded mode (with cracks). There is so a correlation relationship between the extent of cracks and the change in $\mathrm{I}-\mathrm{V}$ characteristics as well as the decrease in efficiency of panels.

As a perspective, we should quantify this relationship: cracks - loss of yield, by finding a way to measure the extent of cracks (area and density) to determine its correlation rates with the electrical parameters of photovoltaic panels.

We also aim to provide a more robust experimental protocol for testing solar panels on site without suffering the effects of climate, lighting or temperature changes.

Finally, we have to test more panels, over a longer period to have more conclusive data.

\section{References}

1. Cynthia E. L. Latunussa, Fulvio Ardente, Gian Andrea Blengini, Lucia Mancini, Life Cycle Assessment of an innovative recycling process for crystalline silicon photovoltaic panels, Solar Energy Materials and Solar Cells, Volume 156, (November 2016).

2. Philippe Gauthier, Quelle sera la véritable durée des vie des panneaux solaires?, Énergie et environnement: Comprendre les enjeux énergétiques et leur impact sur notre monde, (03/03/2018)

https://energieetenvironnement.com/2018/03/03/q uelle-sera-la-veritable-duree-des-vie-despanneaux-solaires/

3. A. Realini, E. Burà, N. Cereghetti, D. Chianese, S. Rezzonico, Mean Time Before Failure of Photovoltaic modules (MTBF-PVm), Annual Report, SUPSI, DCT, LEEE-TISO, (2002)

4. Sanjay Mohan Shrestha, Jaya Krishna Mallineni, Karan Rao Yedidi, Brett Knisely, Sai Tatapudi, Joseph Kuitche, and GovindaSamy TamizhMani, Determination of Dominant Failure Modes Using FMECA on the Field Deployed c-Si Modules 
Under Hot-Dry Desert Climate; IEEE Journal of Photovoltaics (2014)

5. Dirk C. Jordan, John H. Wohlgemuth, and Sarah R. Kurtz, Technology and Climate Trends in PV Module Degradation, the 27th European Photovoltaic Solar Energy Conference and Exhibition Frankfurt, Germany (September 24-28 2012)

6. Dirk C. Jordan, Timothy J. Silverman, John H. Wohlgemuth, Sarah R. Kurtz, Kaitlyn T. VanSant, Photovoltaic Failure and Degradation Modes, National Renewable Energy Laboratory (2017)

7. D.C. Jordan, S.R. Kurtz, K.T. VanSant, J. Newmiller, Compendium of Photovoltaic Degradation Rates (2015)

8. DNV-GL, PV Module Reliability Scorecard Report

https://www.dnvgl.com/publications/pv-modulereliability-scorecard-2017-93448

9. Youichi Hirata, Shouta Noro, Takumi Aoki, Satoru Miyazawa, Diagnosis photovoltaic failure by simple function method to acquire $I-V$ curve of photovoltaic modules string, Photovoltaic Specialists (PVSC), IEEE Conference (2012) 